\title{
EL DERECHO AL JUEZ NATURAL Y LA COMPETENCIA DE LOS TRIBUNALES ESPECIALES (LA APLICACIÓN DE LA REGLA: ELECTA UNA VIA PER PARTEM AD ALIAM POTEST VENIRE). COMENTARIO A LA SENTENCIA DE LA CORTE SUPREMA DE 6 DE AGOSTO 2014. RECLAMO CONTRA SENTENCIA TRIBUNAL DE LA LIBRE COMPETENCIA DICTADA EN LOS AUTOS "SONDA S.A. CONTRA EL SERVICIO DE REGISTRO CIVIL E IDENTIFICACIÓN". ROL CS No 13.972-2013*
}

\section{ALEJANDro RoMero SEguel ${ }^{* *}$}

\section{1) EXPLICACIÓN PREVIA}

La Corte Suprema, en sentencia de 6 de agosto de 2014 procedió a acoger una reclamación reclamación deducida por el Servicio de Registro Civil e Identificación, declarando la incompetencia del Tribunal de Defensa de la Competencia, para conocer de una demanda presentada por empresa Sonda ${ }^{1}$.

La sentencia aborda un problema que se viene haciendo recurrente en la tramitación de causas ante tribunales con competencias que aparentemente son concurrentes, en este caso, el Tribunal de la Contratación Pública y el Tribunal de la Defensa de la Libre Competencia.

Particular relevancia tiene examinar el comportamiento procesal de la parte, a quien se le impide continuar con un debate que ya fue resuelto ante otro tribunal anterior. En el caso comentado, se estimó que después de haberse rechazado la demanda intentada ante el Tribunal de la Contratación Pública no procedía denunciar el tema como una infracción a la libre competencia que fue desestimada.

Sin perjuicio de otros aspectos de interés, los temas procesales que serán objeto de este comentario se contienen en los siguientes considerandos:

DeCIMOQUinTo: Que como surge de la debida inteligencia de las normas citadas la competencia del Tribunal de Contratación Pública

Este trabajo se realiza como investigador responsable dentro del proyecto Fondecyt Regular: "La prejudicialidad en el proceso civil chileno" (No 1130393).

* Profesor de Derecho Procesal de la Universidad de los Andes (CHILE). Doctor en Derecho Universidad de Navarra (España). Licenciado en Ciencias Jurídicas y Sociales de la Universidad de Valparaíso (CHiLE). Correo electrónico: aromero@uandes.cl

1 La sentencia comentada fue pronunciada por la Tercera Sala de esta Corte Suprema integrada por los Ministros Sr. Rubén Ballesteros C., Sr. Héctor Carreño S., Sr. Pedro Pierry A., Sra. Rosa Egnem S., y Sra. María Eugenia Sandoval G. 
se refiere a la impugnación de los actos u omisiones, ilegales o arbitrarios, que se hayan verificado con ocasión de los procedimientos administrativos de contratación con organismos públicos regidos por la Ley $\mathrm{N}^{\circ} 19.886$, vale decir, de aquellos que deben regirse, en lo fundamental, por los principios de libre concurrencia e igualdad de los oferentes y de estricta sujeción a las bases, contenidos en los artículos reproducidos en la consideración precedente.

Esclarecido lo anterior, resulta evidente que la demanda intentada en autos por Sonda S.A., pese a la pretensión de la actora de dotarla de una apariencia propia de la materia que es de competencia del Tribunal de Defensa de la Libre Competencia, incide en cuestiones que son de exclusivo conocimiento del Tribunal de Contratación Pública. En efecto, es la misma demandante quien arguye que el proceder del Servicio de Registro Civil e Identificación ha vulnerado las Bases de la licitación de que se trata y ha transgredido la igualdad entre los oferentes, ya sea alterando la secuencia de la licitación, ya sea creando situaciones de privilegio en favor de uno de los proponentes o, en fin, ignorando las normas de ellas que le obligaban a evaluar la propuesta de Sonda sin excluirla previamente del proceso.

Por su parte, la sentencia reclamada decide el asunto sometido al conocimiento del Tribunal de Defensa de la Libre Competencia basada en un examen, precisamente, de la eventual ilegalidad o arbitrariedad del actuar de la Administración durante el proceso licitatorio y en la adjudicación, en particular en lo relativo a la estricta sujeción a las Bases que esta debe observar y a la igualdad que debe primar entre los proponentes.

Así, los falladores dan por establecido que la demandante no acreditó su experiencia según las Bases (fundamentos octogésimo séptimo y octogésimo octavo); que, conforme a la interpretación que en su concepto debió efectuarse de las secciones que señalan de las Bases Administrativas, tal omisión no debió ser sancionada con la exclusión de Sonda del proceso licitatorio (razonamientos nonagésimo sexto y nonagésimo séptimo); que de acuerdo a los elementos de las Bases que citan no resulta convincente el argumento del demandado referido a que los certificados de experiencia constituyen elementos esenciales de las propuestas técnicas, y concluyen, por el contrario, que las mismas otorgan al Servicio un grado de discrecionalidad en la materia que derivan de la exégesis que de ellas realizan (motivaciones nonagésima octava a centésima primera); que el proceder del Servicio de Registro Civil e Identificación frente a Sonda fue discriminatorio en relación a lo obrado con Morpho, pues si hubiese aplicado un mismo criterio debió declarar inadmisible la oferta de este (reflexión centésima quinta) y así menciona que algunos de los certificados de esta última empresa no cumplen las exigencias formales impuestas 
por el Anexo $\mathrm{N}^{\circ} 25$ de las Bases de la licitación (consideración centésima octava), parte de cuyos requisitos soslayó (juicio centésimo décimo tercero). También dan por establecido que solo se aplicó el máximo rigor al evaluar a Sonda y no así a Morpho (apreciaciones centésima decimacuarta y centésima decimaquinta).

DecimoseXto: Que así las cosas no cabe sino concluir que la materia sometida al conocimiento y decisión del Tribunal de Defensa de la Libre Competencia mediante la demanda de fs. 364 escapa por completo del ámbito de su competencia y se inscribe de lleno en aquel que es propio del Tribunal de Contratación Pública, órgano de la judicatura a quien corresponde exclusivamente decidir en torno a la existencia de actos u omisiones arbitrarios o ilegales verificados con ocasión de procedimientos administrativos de contratación con organismos públicos regidos por la Ley $\mathrm{N}^{\circ} 19.886$ entre la aprobación de las Bases de la licitación y su adjudicación.

De esta manera, las consideraciones vertidas por los sentenciadores relativas al incumplimiento de las Bases del proceso licitatorio de que se trata y a la actuación discriminatoria del demandado deben ser entendidas como lo que son, esto es, como razonamientos que disciernen acerca de la estricta sujeción a las Bases por parte de los intervinientes y de la plena igualdad de los oferentes durante un procedimiento administrativo de contratación con un ente público regido por la Ley $\mathrm{N}^{\circ} 19.886$, aspectos que han sido entregados por el legislador únicamente a los jueces de Contratación Pública sin que en ello quepa intervención alguna a la judicatura de Libre Competencia, máxime si no se advierte, ni la demandante ha manifestado tampoco de manera convincente y clara, de qué manera las actuaciones reprochadas al demandado podrían haber puesto en entredicho o conculcado verdaderamente el bien jurídico por cuya preservación debe velar el tribunal de autos, esto es, la libre competencia en los mercados.

De este modo la única conclusión posible consiste en que el órgano jurisdiccional que ha intervenido en autos no ha podido resolver el asunto de que se trata en los términos en que fue planteado sin ir más allá de la esfera de sus prerrogativas, correspondiendo tan solo desestimar la acción intentada.

DeCimoséptimo: Que la dicha conclusión se ve refrendada por la circunstancia de que el Tribunal de Contratación Pública ya conoció y se pronunció acerca de este conflicto en concreto, lo que sucedió a propósito de la demanda intentada ante él por Sonda S.A. en la causa rol $N^{\circ} 162-2011$, en la que incide un recurso de queja del que ha conocido esta Corte a la vez que de las reclamaciones deducidas en estos autos.

En esos antecedentes los jueces competentes para ello han efectuado el análisis que al efecto les encomienda la ley y han llegado a las con- 
clusiones que allí se leen, sin que en el presente proceso corresponda efectuar declaración alguna sobre el particular, pues ello supondría violentar la competencia que en exclusiva les ha conferido el legislador en esta materia.

\section{2) EL ORIGEN DEL PROBLEMA}

Un problema cada vez más frecuente en nuestro medio es el de la determinación del derecho a ser juzgado por el juez natural. La dificultad proviene del surgimiento de tribunales especiales, que prima facie podrían permitir el conocimiento y juzgamiento de temas conexos, generando hipótesis de prejuzgamiento para un juicio posterior ${ }^{2}$.

En relación a la controversia surgida entre las partes en relación a una licitación pública, la ley ha distribuido competencia absoluta por razón de la materia al Tribunal de la Contratación Pública (TCP). Lo anterior consta en Ley $\mathrm{N}^{\circ} 19.886$, de 30 de julio de 2003, que estableció las bases de los contratos administrativos y prestación de servicios; en el art. $1^{\text {o }}$ de dicha normativa se señala que, los contratos que celebre la Administración del Estado, a título oneroso, para el suministro de bienes muebles, y de los servicios que se requieran para el desarrollo de sus funciones, se ajustarán a las normas y principios del presente cuerpo legal y de su reglamentación. Supletoriamente, se les aplicarán las normas de Derecho Público y, en defecto de aquellas, las normas del Derecho Privado. Para los efectos de esta ley, se entenderán por Administración del Estado los órganos y servicios indicados en el artículo $1^{\circ}$ de la ley No 18.575 , salvo las empresas públicas creadas por ley y demás casos que señale la ley ${ }^{3}$.

2 En efecto, la palabra prejudicial deriva de la voz praejudicium, que significa 'prejuicio, juicio previo o prematuro' de 'prae-' 'antes' judicium 'juicio'. El tema resuelto en este caso ya estaba presente en el proceso romano. Como lo explica Robles Reyes, "a esta incidencia de un proceso sobre otro, atribuidos ambos a órganos distintos, y muy especialmente al supuesto de la concurrencia de un mismo procedimiento de la jurisdicción penal y de la civil, es a lo que se llamó desde la antigua Roma prejudicialidad penal o praeiudicia. Pero esta interesante problemática presenta un contenido distinto según el periodo de la Historia de Roma que contemplemos y el sistema procesal aplicable en ese momento histórico. Desde el principio de los tiempos se han entrecruzado cuestiones civiles y penales en el planteamiento y resolución del litigio y, por tanto, desde que el Derecho Romano fue tal, los magistrados y jueces debieron resolver litigios dando preferencia a las cuestiones civiles, a las penales, o resolver ambas en su conjunto" (Robles Reyes, Juan Ramón (2003), La Competencia jurisdiccional y judicial en Roma, Universidad de Murcia; Servicio de Publicaciones, p. 20).

3 El art. 2o.- Para los efectos de esta ley se entenderá por contrato de suministro el que tiene por objeto la compra o el arrendamiento, incluso con opción de compra, de productos o bienes muebles. Se comprenderán dentro del concepto de contrato de suministro, entre otros, los siguientes contratos: a) La adquisición y arrendamiento de equipos y sistemas para el tratamiento de la información, sus dispositivos y programas y la cesión de derecho de uso de estos últimos. No obstante lo expresado, la adquisición de programas de computación a 
La iniciativa legal referida pretendió dotar a la contratación pública de reglas que actualizaran la normativa anterior, y dentro de ella, dotar a este conflicto de derecho económico de un preciso juez natural, para obtener, de paso, una modernización en la contratación del Estado ${ }^{4}$.

Por lo mismo, si se ha creado un órgano especial para la tutela de los derechos que se infrinjan dentro del marco de una licitación publica, cualquier intento por transformar esa discusión en un problema de libre competencia no puede prosperar, atendido que los agentes económicos que participan en esa esfera de la contratación pública ya cuentan con un mecanismo especial de protección.

Por su parte, el art. 24 de la referida ley estableció que el TCP será competente para "conocer de la acción de impugnación contra actos u omisiones, ilegales o arbitrarios, ocurridos en los procedimientos administrativos de contratación con organismos públicos regidos por esta ley". La misma norma indica que "la acción de impugnación procederá contra cualquier acto u omisión ilegal o arbitrario que tenga lugar entre la aprobación de las bases de la respectiva licitación y su adjudicación, ambos inclusive".

\section{3) LA VIS ATRACTIVA DE LAS NORMAS DE COMPETENCIA POR RAZÓN DE LA MATERIA}

La opción por atribuir competencia por razón de la materia al TCP produce una vis atractiva, que debe inhibir la actuación de otros tribunales que puedan entrar a conocer de los asuntos que solo corresponden a ese juez natural.

En este caso, la Corte Suprema entendió que por el solo hecho de haberse promovido un primer debate, dentro de la esfera de la contratación pública, procedía declarar la incompetencia del TDLC, al tratarse de una disputa surgida con ocasión de un procedimiento administrativo de selección de contratistas.

Sin embargo, el problema de competencia resuelto por la Corte Suprema ya había sido advertido en la tramitación por algunos parlamentarios. Lo anterior consta de la historia del establecimiento del TCP en la discusión de la Ley $\mathrm{N}^{\circ} 19.886$, de 30 de julio de 2003, sobre las bases de

medida se considerará contratos de servicios; b) Los de mantenimiento de equipos y sistemas para el tratamiento de la información, sus dispositivos y programas cuando se contrate conjuntamente con la adquisición o arrendamiento, y c) Los de fabricación, por lo que las cosas que hayan de ser entregadas por el contratista deben ser elaboradas con arreglo a las características fijadas previamente por la Administración, aun cuando esta se obligue a aportar, total o parcialmente, los materiales.

4 Una mayor explicación, Moraga Klenner, Claudio (2007), Contratación Administrativa, Santiago: Editorial Jurídica de Chile, pp. 283-309. 
los contratos administrativos y prestación de servicios. De un modo directo, previó este conflicto promovido ante el TCP y el TDLC la prevención del Senador Jovino Novoa, cuando puntualizó que, "hay un aspecto de la iniciativa que también ha surgido con motivo de la discusión de otros proyectos, cual es el establecimiento de un tribunal especial. Y sucede que se están creando varios tribunales para lo contencioso administrativo". "Por eso, quizás sería del caso determinar si es conveniente o no tal cantidad de esos órganos. Tenemos tribunal de propiedad industrial, tribunal de libre competencia; ahora se agrega el de contratación pública, y dentro de poco vendrán los tribunales tributarios. No sé si estamos legislando en forma adecuada" 5 .

5 Historia de la Ley No 19.886, p. 320. También en la Discusión en el Senado quedó constancia que don Enrique Silva C., en relación a la creación del TCP, "estimó que la creación de este tribunal especial da cuenta de una suerte de desorden en la formulación de políticas y de propuestas legislativas por parte del Ejecutivo. En efecto, sostuvo, el Gobierno ha definido como una de sus principales preocupaciones la modernización del Estado, sobre la cual ha consultado al Senado, que creó una Comisión especial para tal efecto; y, por otra parte, existe en el Ministerio de Justicia una comisión encargada de estudiar la creación de los tribunales contenciosos administrativos, para dar cumplimiento en mejor forma al inciso segundo del artículo 38 de la Constitución Política de la República. En esa medida, no resulta explicable que, en forma simultánea, sea el mismo Ejecutivo el que esté impulsando un proyecto de ley sobre bases de los procedimientos administrativos, ya despachado por esta Corporación; otro, sobre la creación de un tribunal especial, el de Defensa de la Libre Competencia; y un tercero, relativo a la creación de este otro tribunal especial para casos específicos de contratación pública, todos ellos respaldados por distintas Secretarías de Estado". "Consideró que, a la luz de todos esos antecedentes, puede decirse, a lo menos, que no se entiende la concepción que hay tras la creación de este Tribunal de Contratación Pública, para no aventurar que se trata de una concepción burocrática, inconciliable con una adecuada lógica legislativa". En la misma acta consta que "el señor Ministro de Justicia señaló que el Ejecutivo estudió con varios parlamentarios y ex parlamentarios la creación de tribunales tributarios, de lo cual surgió el propósito de establecer tribunales contencioso administrativos, que tengan la totalidad de la competencia para conocer este tipo de materias y otras que se están analizando". "Sin embargo, prosiguió, como ello significa un cambio estructural de fondo, lo que implica un mayor tiempo de estudio, esta se ha centrado en los tribunales tributarios en particular, con el propósito de que, una vez resuelta esta materia, se retome el análisis de lo contencioso administrativo en su globalidad" (Historia de la Ley No 19.886, pp. 196-197). Más adelante el mismo Parlamentario vuelve sobre el tema, indicando que, “(...) el sistema al que se está recurriendo no es el más adecuado, desde el punto de vista de la racionalidad administrativa. Con este procedimiento se está eludiendo el problema de fondo, que se refiere precisamente a la creación de los tribunales contencioso administrativos, que es una deficiencia que se hace notar. Luego de la Reforma Constitucional de 1989 , en que se cambió la referencia que hacía el artículo 38 a los tribunales contencioso administrativos, por la alusión a los tribunales que determine la ley, todas las cuestiones de aquella naturaleza quedaron sometidas a la jurisdicción ordinaria. A partir de ello, mientras no se resuelva este problema, podría evaluarse la idea de establecer una reclamación ante los tribunales ordinarios de justicia, lo que evitaría que el Estado se llene de tal cantidad de tribunales especiales, que se entorpezca la marcha de la administración de justicia”. 


\section{4) LA OMISIÓN DE UNA SOLUCIÓN TÉCNICA QUE SE APRECIA EN OTRAS LEYES}

La deficiente regulación del TCP, en su interrelación con otros componentes del órgano jurisdiccional, se agrava por la falta de una técnica utilizada al establecer otros tribunales que conocen de hechos que pueden ser comunes al TDLC, como ocurre con la regulación de la competencia desleal Ley No 20.169. El art. 10 de este último cuerpo legal dispone que, "si la sentencia firme establece que han existido uno o más actos de competencia desleal, el tribunal que la dictó deberá remitir todos los antecedentes del juicio al Fiscal Nacional Económico, quien tendrá la facultad de requerir al Tribunal de Defensa de la Libre Competencia, atendidas la gravedad de la infracción o la extensión del perjuicio provocado, la aplicación de la multa correspondiente de conformidad con esta ley".

Como se puede apreciar, ante un ilícito de competencia desleal la parte afectada tiene la posibilidad de deducir una demanda ante el Juez Civil, pero no puede -al mismo tiempo- interponer su pretensión ante el TDLC por los mismos hechos. La ley señala que debe esperar la sentencia y es el juez de la causa el que puede enviar los antecedentes a quien protege el interés público en materia de libre competencia para que, si lo estima pertinente, interponga el respectivo requerimiento.

$Y$ es que la parte afectada por un ilícito de competencia desleal que sea relevante para la libre competencia, previo a la interposición de la acción, tiene potencialmente la sede civil y la sede ante el TDLC. Si la conducta procesal es interponer previamente la demanda civil, no podría al mismo tiempo interponer una acción ante el TDLC y, deberá esperar la sentencia definitiva en que el juez envíe los antecedentes a la FNE, para que dicho órgano, pondere el mérito de la sentencia y, en base a la misma, interponga el respectivo requerimiento.

A nuestro entender, la misma solución debería adoptarse en un caso en que una arbitrariedad e ilegalidad cometida en un procedimiento de selección de contratistas sea relevante para la libre competencia. En dicho escenario, la parte afectada tiene potencialmente dos sedes para impugnar dicha arbitrariedad, la sede ante el TCP y ante el TDLC. Si se opta por la primera sede, esto es el TCP, no puede la mismas arbitrariedad o ilegalidad ventilarse paralelamente en los dos tribunales. Necesariamente deberá optar por acudir al TDLC o, bien, esperar la calificación de arbitrariedad e ilegalidad por parte de TCP como condición previa de acudir al TDLC.

\section{5) EL COMPORTAMIENTO PROCESAL ANTERIOR DE LA PARTE}

La sentencia también utiliza, como un criterio para la aplicación del derecho, considerar la conducta procesal de la parte. En el caso concreto, 
el hecho que la actora ya había iniciado con anterioridad un juicio ante el TCP fue un factor determinante para la declaración de incompetencia.

La pauta anterior resulta de interés por introducir a nuestra práctica forense una elaboración que la doctrina procesal contemporánea viene examinando, en el estudio de deber de coherencia en el proceso civil ${ }^{6}$.

Según la RAE la coherencia significa: 1) "conexión, relación o unión de unas cosas con otras", 2) "Actitud lógica y consecuente con una posición anterior".

En el campo jurídico, lo anterior se proyecta como un estándar de sustentabilidad lógica; como un estándar de valoración que impone deberes a las partes; $y$, como un elemento que determina la valoración de la prueba. En el caso comentado, la Corte Suprema ha optado, en mi opinión, por considerar la sustentabilidad lógica que impone a todo litigante las consecuencias de elegir una vía procesal. Como decían los clásicos: elegida una vía procesal por una parte no se podía acudir a otra (electa una via per partem ad aliam potest venire $)^{7}$.

\section{CONCLUSIONES}

$\left.1^{\circ}\right)$ La proliferación de procesos y de tribunales especiales hace surgir problemas procesales en la determinación de la competencia.

$2^{\circ}$ ) En la determinación del derecho al juez natural debe primar la competencia asignada por razón de la materia, evitando que puedan actuar juzgado temas comunes en forma paralela o con posterioridad dos o más tribunales.

6 Sobre el tema, Carretta Muñoz, Francesco (2008), "Deberes procesales de las partes en el proceso civil chileno: referencia a la buena fe procesal y al deber de coherencia” en Revista de Derecho, Vol. XXI, pp. 101-127; Del mismo autor, La Coherencia en el Proceso Civil, Santiago: LegalPublishing, 2013, pp. 1-364; Londollo Jaramillo, Mabel (2008), Sobre las conductas procesales de las partes, Medellín: Universidad de Medellín, pp. 17-196.

7 Según Domingo, esta regla tiene su fuente en Decio, Regula, 301.6, p. 117. También se cita a Papiniano. Ulpiano D. 18.3.4.2. Domingo, Rafael, (2000), Reglas jurídicas y aforismos, Reglas juridicas y aforismos, Pamplona: Aranzadi, p. 48. 